\title{
INVESTIGATION OF LUBRICATING OILS FROM RENEWABLE RESOURCES FOR CRYOGENIC MINIMUM QUANTITY LUBRICATION
}

\author{
T. Meier ${ }^{1 *}$, D. Gross ${ }^{1}$, N. Hanenkamp ${ }^{1}$ \\ ${ }^{1}$ University Erlangen-Nuremberg, Institute for Resource and Energy Efficient Production Systems, Dr.-Mack-Str. 81, \\ 90762 Fürth, Germany \\ *Corresponding author; e-mail: trixi.meier@fau.de
}

\begin{abstract}
Cryogenic minimum quantity lubrication using liquid carbon dioxide $\left(\mathrm{CO}_{2}\right)$ has increasingly become the focus of research in recent years. With this cooling strategy it is possible to cool and lubricate the cutting zone individually by regulating the oil and liquid $\mathrm{CO}_{2}$ flow. The oil used has a significant influence on the process stability and performance. The aim of this study is to identify the influence of 15 different base oils from renewable sources on a milling process of $\mathrm{X} 2 \mathrm{CrNiM017-12-2}$ with cryogenic minimum quantity lubrication. For this purpose, a non additivated sunflower, coconut and rapeseed oil and additional biobased oils, such as synthetic ester and fatty alcohol, will be tested and compared to a conventional mineral oil regarding wear, process forces and productivity. In addition, the impact of the bio-based oils on rough turning of $\mathrm{X} 2 \mathrm{CrNiMo17-12-2}$ and finishing turning of $100 \mathrm{Cr} 6$ with cryogenic minimum quantity lubrication is evaluated and compared to the milling performance. The results have been analyzed in comparison to conventional emulsion flood cooling and recommendations have been given for the future development of sustainable lubricants to be applied with cryogenic cooling strategy.
\end{abstract}

Keywords:

CMQL; milling; turning; bio-based oils; carbon dioxide

\section{INTRODUCTION}

The increasing importance of environmentally friendly and resource-saving production in industry calls for innovative and sustainable machining processes. With conventional cooling concepts, materials can only be machined with a significant expenditure of energy and resources.

The most common cooling concept is (high-pressure) wet machining with pressures up to $p>80$ bar. This involves the use of large quantities of water, cooling media and chemical additives, which are considered to be environmentally incompatible and hazardous to health. One possibility of an alternative and sustainable cooling concept is cryogenic process cooling in combination with minimum quantity lubrication (CMQL). In this cooling concept, cryogenic media such as carbon dioxide $\left(\mathrm{CO}_{2}\right)$ is used to cool the process zone while the lubrication medium ensures the lubrication function between the tool and the workpiece at very low flow rates (up to $50 \mathrm{ml} / \mathrm{h}$ ).

The aim of this study is to identify the influence of 15 different base oils from renewable sources on a milling process and two different turning processes in comparison to conventional flood cooling regarding wear, process forces and productivity.

\section{STATE OF THE ART}

Metalworking fluids (MWFs) for machining are divided into water-miscible and non-water-miscible MWFs. According to VDI Guideline 3397, cutting fluids have the three main tasks: cooling, lubricating and rinsing [VDI 3397 2007]. They are intended to dissipate the heat generated during chip removal from the point of action, reduce friction between the tool and the workpiece and remove the chips. Non-water-miscible metalworking oils consist of a base oil and application-specific additives. Base oils in metalworking can be divided into the groups "mineral oils", "synthetic oils" and "oils from renewable raw materials" [Bartz 2010]. Lubricants from renewable raw materials are usually produced from fully refined vegetable oils (e.g. rapeseed oil). Additives are added to the base oils to obtain chemical-physical properties tailored to the respective application [Dettmer 2006]. These include, for example, extreme pressure additives, anti-wear additives, corrosion protection additives, antioxidants, antifog additives and defoamers. The mass fraction of these additives can be between $3 \%$ and up to $45 \%$ [Baumann 1996; Weinert 1999].

The following Tab. 1 gives an overview of the functions realized in different cooling lubrication concepts according to VDI 3397. 
Tab. 1: Overview of different cooling concepts.

\begin{tabular}{cccc}
\hline strategy & cooling & lubrication & rinsing \\
\hline flood & + & + & + \\
dry & - & - & - \\
$\mathrm{MQL}$ & - & + & - \\
$\mathrm{CO}_{2}$ & ++ & - & - \\
$\mathrm{CO}_{2}+\mathrm{MMS}$ & ++ & + & - \\
\hline
\end{tabular}

\subsection{Flood cooling}

The most common concept, especially for machining difficult-to-machine materials (e.g. titanium and nickelbased alloys), is (high-pressure) wet machining ( $p \geq$ 80 bar). A number of problems are associated with the use of cooling lubricants. Large quantities of water, lubricants and chemical additives are used, which are considered to be environmentally incompatible and hazardous to health. Due to the high consumption of coolant lubricants in metal cutting, approximately $800,000 \mathrm{t}$ of hazardous waste is generated in Germany each year [Herrmann 2017]. The use of cooling lubricants in recycling processes requires cost-intensive reprocessing and maintenance, which is only possible over a limited period of time and also involves quality risks. If coolant lubricants cannot be reprocessed further, these environmentally hazardous substances must be disposed under strict legal conditions. In addition, a considerable amount of electrical energy must be used to operate the pumps and filter systems for coolant in the machine tool. The disposal problem also affects the processing of the produced chips. Wet machined components must also be cleaned after machining. The plant technology required for these processes requires space in the production facility, additional energy and auxiliary materials. In addition, the equipment required for this purpose incurs investment costs for acquisition and costs for ongoing operation. The costs for procurement, care and maintenance as well as disposal of cooling lubricants and the corresponding plant technology can significantly exceed the tool costs in a production process. [Reich 2002; Abele 2012]. Another problem is the health risks for employees. In addition to the regular constituents, bacteria and microorganisms that spread in the cooling lubricant are also to be considered problematic. Possible effects for machine operators include skin diseases, infections and allergies [DGUV Information 209051 2016; Schebek 2016]. It should also be noted that continuous spread of cooling lubricant mainly takes place via the workpiece and the chips. The oil content in grinding slurries can be up to $80 \%$ [Dettmer 2006]. In larger transfer lines, several cubic meters of coolant can be dragged out daily. Klocke, for example, describes a transfer line with a coolant volume of $60 \mathrm{~m}^{3}$ from which up to $6 \mathrm{~m}^{3}$ of coolant is dragged out daily [Klocke 2008]. The volume of the dragged-out coolant must then be replenished with fresh lubricant. Due to these disadvantages, efforts have been made for many years to either completely avoid or significantly reduce the use of MWFs in metalworking. The use of cryogenic media is discussed below.

\subsection{Cryogenic cooling}

The machining of difficult-to-machine materials is becoming increasingly important in various industries. This is due to the particularly good mechanical and, in some cases, chemical properties of these materials, which enable the achievement of specific development goals. The example of aerospace shows that high-strength materials, such as the titanium alloy Ti6Al4V, are increasingly used to design lightweight and efficient aircraft [Denkena 2018]. Likewise, this trend is also noticeable in other industries, such as the automotive industry [Walter AG 2018]. Machining of these materials is accompanied by increased thermo-mechanical stresses on the tool, so that an efficient cooling lubrication concept is required to ensure adequate removal of process heat and reliable lubrication to reduce friction. Conventional cooling lubrication strategies, such as full-jet cooling with water-mixed coolants, have reached their limits. More efficient coolants can help to extend tool life and increase metal removal rates [Abele 2012]. This allows a more economical production of corresponding components. Since 1999, the number of scientific papers on cryogenic cooling has been steadily increasing. First investigations focused on liquid nitrogen ( $\left.\mathrm{LN}_{2}\right)$, which cools up to $\mathrm{T}=-196{ }^{\circ} \mathrm{C}$ [Hong 2000; Wang 2000]. Due to the fact that tool wear could be reduced in difficult-to-machine alloys such as Ti6Al4V or X5CrNi18-10, the range of materials steadily expanded. Since De Chiffre investigated the influence of $\mathrm{CO}_{2}$ as cooling in grinding and Hesterberg and Wittkop in turning, $\mathrm{CO}_{2}$ has been increasingly used as a direct cooling medium [Hesterberg 2005; Chiffre 2007]. Cryogenic cooling is based on the Joule-Thomson effect, in which $\mathrm{CO}_{2}$ is passed through a conduit of constant pressure and volume to the point of exit. There, a pressure drop and expansion take place, which initiates an energy conversion and realizes a cooling effect down to $\mathrm{T}=-78.5^{\circ} \mathrm{C}$. Above the sublimation point, $\mathrm{CO}_{2}$ can be liquefied at room temperature and stored in standpipe cylinders without further technical effort. In contrast to conventional MWFs, cryogens only realize the cooling function in the machining process, so that additional support with MQL can further improve the performance and the machining result [Gross 2016; Pereira 2016; Park 2017]. Commercially available solutions differ in the cryogenic media used ( $\mathrm{LN}_{2}$, $\mathrm{CO}_{2}$ ), the type of supply (single or multi-channel) and route of feed (internal or external).

\subsection{Cryogenic cooling with minimum quantity lubrication}

Cryogenic MQL has significant potential for cooling lubrication of the machining of difficult-to-machine materials. Cooling is achieved with liquid carbon dioxide and effectively reduces the thermal stress on the cutting edge of the tool. In combination with a continuously applied $M Q L$, which reduces the friction between tool and workpiece, an increase in tool life and cutting values can be achieved in comparison to conventional wet machining and to $\mathrm{MQL}$ without $\mathrm{CO}_{2}$ cooling [Biermann 2018]. In the singleflute feed, the oil is pumped into the $\mathrm{CO}_{2}$ stream and transported by it to the effective point. The small lubricant quantities (approx. $5 \mathrm{ml}$ to $50 \mathrm{ml}$ per hour) evaporate almost completely during machining, which means that the machined workpieces usually do not have to be cleaned afterwards. Furthermore, there are economic advantages due to lower investment and operating costs for the required equipment and the reduction of disposal costs for chips and coolant. Ecological advantages include the reduced impact on employees and the environment due to the lubricants and their additives [BGI/GUV-I 718 2010]. The cooling lubrication strategy of cryogenic MQL is thus able to represent the main tasks of cooling and lubrication in one machining process. In addition, the aspects of sustainability and health are improved.

\subsection{Bio-based lubricants}

The use of bio-based lubricants for cryogenic minimum quantity lubrication represents a further increase in ecological compatibility. Bio-based oils consist of at least $25 \%$ renewable raw materials, are at least $60 \%$ biodegradable and, in accordance with CLP Directive $1272 / 2008 / E C$, do not have to be labeled as environmentally hazardous [DIN CEN/T 16227 2011]. 
Some of the ester cooling lubricants produced on the basis of rapeseed or sunflower oil, for example, have properties that predestine them for special machining tasks. Examples include lower evaporation losses and better lubricity compared to mineral oil-based lubricants [Czichos 2015]. Pure rapeseed or sunflower oils are not used in industry due to aging, sticking, resinification, etc. so far, biologically based lubricants have not been used for wet machining in metal cutting. The reason for this is that they are much more expensive than mineral oil-based lubricants, due to the high cost of synthesis. However, the lubricant quantities consumed in MQL are many times lower, which is why this disadvantage has less of an impact here than in wet machining. Tests with various bio-based oils show that they are fundamentally suitable for use as cooling lubricants in machining. Tests also show that bio-based lubricants can be superior to mineral-based comparative products in terms of performance. When bio-based oils are used, reduced cutting forces, lower heat generation at the point of action, longer tool life and improved surface qualities have been observed [Belluco 2001; Chiffre 2002; Belluco 2004; Abdalla 2007; Xavior 2009; Winter 2012; Mannekote 2018] This is especially true for the application of MQL [Rahim 2009; Lawal 2012].

In the "KryoLEAN" project, the Chair of Resource and Energy Efficient Production Machines at the FAU-University of Erlangen-Nuremberg was able to demonstrate that no supercritical or gaseous state is required to use $\mathrm{CO}_{2}$ as a carrier medium for an MMS technology [Gross 2016]. In the developed mixing unit, $\mathrm{CO}_{2}$ is taken from a standpipe bottle in liquid state only and the density, temperature and mass flow rate are determined via a Coriolis flow meter. $\mathrm{CO}_{2}$ mass flow rates between $\dot{m}=3 \mathrm{~kg} / \mathrm{h}$ and $20 \mathrm{~kg} / \mathrm{h}$ can be set via valves. An additional precision reciprocating pump delivers a low-temperature oil to a minimum flow rate of $\dot{\mathrm{m}}=0.1 \mathrm{ml} / \mathrm{min}$, which is injected into the $\mathrm{CO}_{2}$ stream and transported to the effective point as an emulsion or twosubstance mixture. With this experimental setup, milling tests with external coolant supply as well as drilling tests with internal coolant supply could be successfully implemented [Hanenkamp 2018]. In preliminary tests of the Chair of Resource and Energy Efficient Production Machines, several lubricants were already compared with each other with regard to tool wear by using the existing cryogenic supply system. The lowest tool wear occurred here when a bio-based ester was used. The evaluation of the bending moments acting on the tool further confirms this. The resinification effects on components of the machine tool have not been detected so far. On the one hand, this may be due to the powerful extraction system, but on the other hand it may also be due to the relatively short application period.

\section{EXPERIMENTAL SETUP}

In the following chapter, the test setup is described in more detail with regard to the selected base oils, processing machines, workpieces and tools.

\subsection{Base oils}

In the experiments, the influence of bio-based base oils on machining with cryogenic minimum quantity lubrication is investigated and 15 different bio-based base oils from three lubricant manufacturers are selected for this purpose. The base oils do not contain any additives. The proportion of renewable raw material should be as high as possible, but also all four groups: synthetic esters, natural esters, fatty alcohols and natural hydrocarbons should be covered. The CMQL tests will be carried out using a hydrocrack oil, which is also unadditivated, as a reference. The results of the CMQL are compared with emulsion flood cooling $(8 \%$ Blasocut BC 935) as the standard cooling strategy, in the following text and evaluation always referred to as KSS. The following Tab. 2 contains the abbreviation of the respective oils and additionally their chemical structures and the contents of renewable raw material.

Tab. 2: Examined oils.

\begin{tabular}{ccc}
\hline name & chemical structure & $\begin{array}{c}\text { RRM content } \\
\text { (Renewable Rawmaterial) }\end{array}$ \\
\hline SE 01 & monoester & $75-99 \%$ \\
SE 02 & azelaic acid ester & $25-50 \%$ \\
SE 03 & bis (2-ethyl-hexyl) azelate & $50-75 \%$ \\
SE 04 & monoester & $48 \%$ \\
SE 05 & diester & $92 \%$ \\
SE 06 & triester & $81 \%$ \\
SE 07 & monoester & $100 \%$ \\
SE 08 & dicarboxylic acid esters & $<40 \%$ \\
SE 09 & monoester & $>50 \%$ \\
SE 10 & polyolester & $>80 \%$ \\
FA 01 & fatty alcohol & $0 \%$ \\
NE 01 & triglyceride & $100 \%$ \\
NE 02 & triglyceride & $100 \%$ \\
NE 03 & triglyceride & $100 \%$ \\
KW 01 & - & $75-99 \%$ \\
KW 02 & hydrocrackoil & $0 \%$ \\
\hline SE: synthetic ester & FA: fatty alcohol \\
NE: natural ester & KW: natural hydrocarbon \\
\hline
\end{tabular}

For the selection of the oils, the relevant chemical properties are defined and the associated measurement method is determined. In order to comply with the competitive secrets of the individual lubricant manufacturers, value ranges are defined separately for each property. This is shown in Tab. 3 below. The selected oils cover all defined ranges.

Tab. 3: Chemical characteristics and value areas.

\begin{tabular}{|c|c|c|c|}
\hline characteristic & $\begin{array}{c}\text { measuring } \\
\text { method }\end{array}$ & $\begin{array}{l}\text { value } \\
\text { areas }\end{array}$ & unit \\
\hline \multirow{2}{*}{ viscosity 40} & \multirow{2}{*}{ Stabinger } & $<10$ & \multirow{2}{*}{$\mathrm{mm}^{2} / \mathrm{s}$} \\
\hline & & $10-20$ & \\
\hline \multirow{2}{*}{ viscosity 100} & \multirow{2}{*}{ Stabinger } & $<2$ & \multirow{2}{*}{$\mathrm{mm}^{2} / \mathrm{s}$} \\
\hline & & $2-5$ & \\
\hline \multirow{3}{*}{ viscosity index } & \multirow{3}{*}{ Stabinger } & $<90$ & \multirow{6}{*}{$\mathrm{g} / \mathrm{ml}$} \\
\hline & & $120-150$ & \\
\hline & & $>150$ & \\
\hline \multirow{3}{*}{ densitiy $\left(15^{\circ} \mathrm{C}\right)$} & \multirow{3}{*}{ DIN 51757} & $<0,08$ & \\
\hline & & $0,08-0,09$ & \\
\hline & & $>0,9$ & \\
\hline \multirow{3}{*}{$\begin{array}{l}\text { chain length } \\
\text { (number of } \\
\text { c-atoms) }\end{array}$} & & $<$ C10 & \\
\hline & & $\mathrm{C} 10-\mathrm{C} 20$ & \\
\hline & & $>\mathrm{C} 20$ & \\
\hline \multirow{3}{*}{ polarity } & \multirow{3}{*}{ Non Polarity Index } & Nonpolar & \\
\hline & & weak polar & \\
\hline & & Polar & \\
\hline \multirow{3}{*}{ pourpoint } & \multirow{3}{*}{ DIN ISO 3016:2017 } & $>-50$ & \\
\hline & & -50 to -80 & ${ }^{\circ} \mathrm{C}$ \\
\hline & & $<-80$ & \\
\hline \multirow{2}{*}{ ester content } & & 0 & \multirow{2}{*}{$\%$} \\
\hline & & $>95$ & \\
\hline \multirow{2}{*}{ water content } & \multirow{2}{*}{ DIN 51777-1 } & $<0,05$ & \multirow{2}{*}{$\%$} \\
\hline & & $0,05-0,1$ & \\
\hline sulfur content & DIN 51399-1 ICP & $<0,01$ & $\%$ \\
\hline phosphor content & DIN 51399-1 ICP & $<0,01$ & $\%$ \\
\hline
\end{tabular}

MM Science Journal | 2021 | NOVEMBER - Special Issue on HSM2021 


\subsection{Machines and measuring equipment}

For the milling reference process, the 3 -axis CNC milling machine of the type DNM 500 from the company Doosan available at the chair is used. The chair's CLX 350 lathe is used to carry out the turning processes, Fig 1 . The REP cryogenic mixing system, described above, is used on both machines.

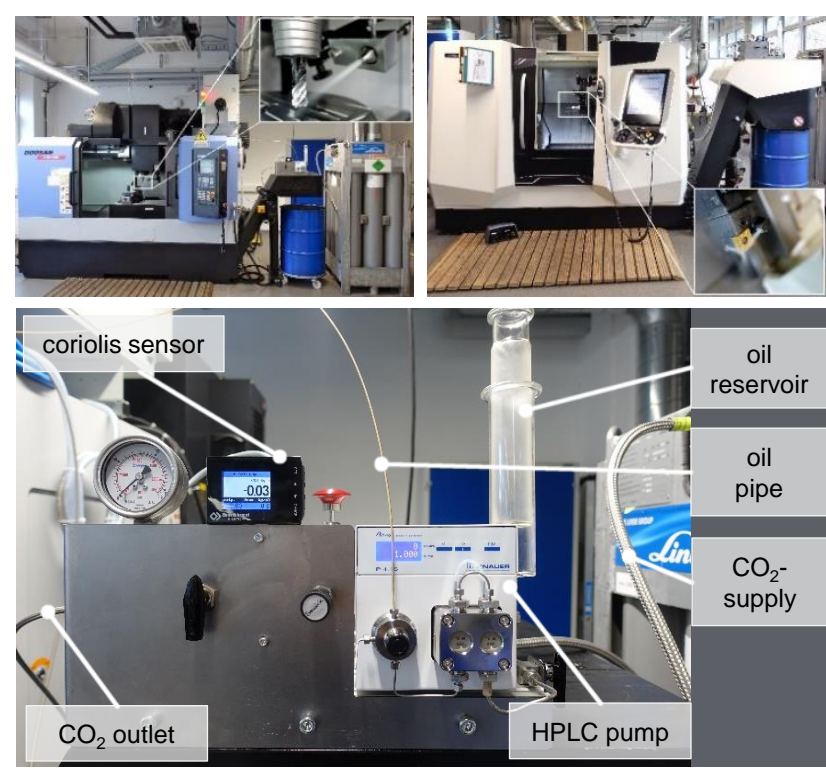

Fig. 1: Machine setup and cryogenic mixing unit.

For the analysis of the created surfaces, more precisely for the measurement of the surface roughness characteristics, the roughness measuring device W10 of the company Hommel etamic with an inductive skid probe is used. The VHX-5000 measuring microscope from Keyence is used to document the wear on the indexable inserts and to analyze the edge zone. The occurring cutting forces during milling are recorded with the sensory tool holder "Spike" from the company pro-micron GmbH \& Co. KG. Strain gauges in the tool holder record the forces that occur and a temperature sensor records the temperature of the tool holder at a measuring rate of up to $2.5 \mathrm{kHz}$ and a measured value resolution of up to 15 bits. In addition to the bending moment $\mathrm{MB}$ in the $\mathrm{X}$ and $\mathrm{Y}$ directions, the axial force $\mathrm{Fz}$ and the torsional moment are analyzed and recorded. The cutting forces during turning are recorded with the Kistler piezo-electric 3-component dynamometer 9129A and amplified with the $5167 \mathrm{~A}$ charge amplifier and data acquisition system. The dynamometer measures cutting forces up to $8 \mathrm{kN}$ in the measuring ranges in $\mathrm{Fx}$ and $\mathrm{Fz}$ from -5 to $5 \mathrm{kN}$ and in Fy from -8 to $8 \mathrm{kN}$. The charge amplifier has 8 channels with a sampling rate of up to $100 \mathrm{kHz}$.

\subsection{Materials/tools}

In addition to the stainless steel X2CrNiMo17-12-2 (1.4404), the rolling bearing steel 100Cr6 (1.3505) is machined in the tests and the influence of the workpiece material on the choice of bio-based lubricant base oil for cryogenic minimum quantity lubrication is investigated. The stainless steel is milled and rough turned and the rolling bearing steel is finish turned. The dimensions of the workpieces are shown in Tab. 4. All workpieces are premachined to realize equal starting conditions for the test runs.

Tab. 5 describes the tools used in more detail. These are standard tools from the industry for the respective machining. The tools including the coating have therefore not yet been optimized for cryogenic machining. The milling cutter used has internal cooling channels. In subsequent investigations, the internal supply of the $\mathrm{CO}_{2}$-oil mixture will be realized and the influence of the choice of the base oil will be investigated in more detail.

Tab. 4: Materials investigated by process.

\begin{tabular}{|c|c|c|c|}
\hline $\begin{array}{c}\text { manufacturing } \\
\text { process }\end{array}$ & milling & $\begin{array}{c}\text { rough } \\
\text { turning }\end{array}$ & $\begin{array}{l}\text { finish } \\
\text { turning }\end{array}$ \\
\hline material & $\begin{array}{c}1.4404 \\
\text { X2CrNiMo17-12- }\end{array}$ & $\begin{array}{c}1.4404 \\
2 \text { X2CrNiMo17-12-2 }\end{array}$ & $\begin{array}{l}1.3505 \\
100 \mathrm{Cr} 6\end{array}$ \\
\hline length & $148 \mathrm{~mm}$ & $180 \mathrm{~mm}$ & $80 \mathrm{~mm}$ \\
\hline width & $148 \mathrm{~mm}$ & & \\
\hline diameter & & $68,6 \mathrm{~mm}$ & $130 \mathrm{~mm}$ \\
\hline
\end{tabular}

Tab. 5: Tools investigated by process.

\begin{tabular}{cccc}
\hline $\begin{array}{c}\text { manufacturing } \\
\text { process }\end{array}$ & milling & $\begin{array}{c}\text { rough } \\
\text { turning }\end{array}$ & $\begin{array}{c}\text { finish } \\
\text { turning }\end{array}$ \\
\hline $\begin{array}{c}\text { tool } \\
\text { coating } \\
\text { diameter/ } \\
\text { tip radius }\end{array}$ & solide carbide & $\mathrm{TiAIN}-\mathrm{HC}$ & $\mathrm{CBN}$ \\
\hline
\end{tabular}

\section{EXPERIMENTAL TESTS}

In addition to the bio-based base oils, the three test series milling, rough turning and finish turning are also carried out with the reference hydrocrack mineral oil and, for comparison, with an emulsion cooling strategy. For all test series, the same MWF concentrate is used for the emulsion. Each test series, i.e. each oil, is repeated three times in order to obtain a statement on the reproducibility of the results and thus on the process reliability. This applies to all three machining processes: milling, rough turning and finish turning.

The experimental setup is shown in Fig. 2. During milling, cryogenic minimum quantity lubrication is supplied via an external nozzle and all 15 bio-based base oils and references are tested. The workpiece is clamped in a vice on the machine table. On the other hand, during turning, only the nine best oils are tested further. The workpiece is clamped in the jaw chuck during rough turning and between centers during finishing turning.

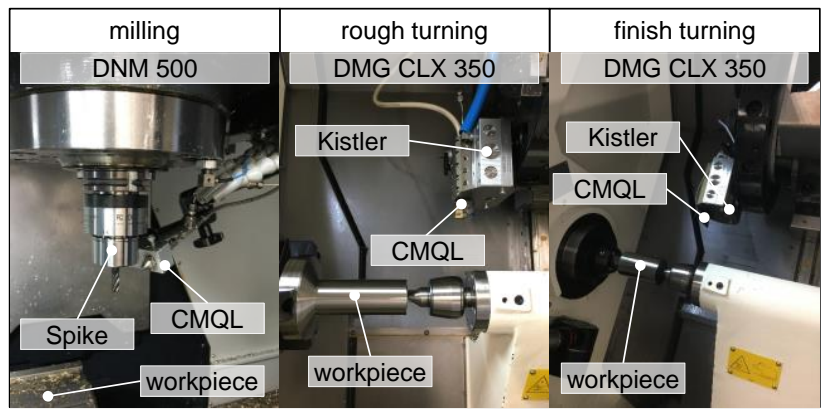

Fig. 2: Experimental setup.

The machining parameters can be taken from the Tab. 6 below. These are empirical values from industry that are optimized for cryogenic machining. The oil flow rate is selected as constant for all three test series, but the $\mathrm{CO}_{2}$ flow rate is adapted to the respective type of machining. For the sake of clarity, the process parameters are not mentioned repeatedly in the presentation of the results, since the values mentioned here are not changed during the tests. 
Tab. 6 : Process parameter.

\begin{tabular}{ccccc}
\hline parameter & milling & $\begin{array}{c}\text { rough } \\
\text { turning }\end{array}$ & $\begin{array}{c}\text { finish } \\
\text { turning }\end{array}$ & unit \\
\hline $\begin{array}{c}\text { material } \\
\text { cutting speed } \mathbf{v}_{\mathbf{c}}\end{array}$ & 1.4404 & 1.4404 & 1.3505 & \\
rotational speed $\mathbf{n}$ & 10500 & 160 & 200 & $\mathrm{~m} / \mathrm{min}$ \\
feed $\mathbf{f}_{\mathbf{z}} / \mathbf{f}$ & 0,06 & 0,25 & 0,12 & $\mathrm{~mm} / \mathrm{rev}$ \\
cutting width $\mathbf{a}_{\mathbf{e}}$ & 0,8 & & & $\mathrm{~mm}$ \\
$\begin{array}{c}\text { cutting depth } \mathbf{a}_{\mathbf{p}} \\
\text { oil flow rate }\end{array}$ & 8 & 3 & 0,1 & $\mathrm{~mm}$ \\
$\mathbf{C O}_{\mathbf{2}}$ flow rate & 8 & 0,8 & 0,8 & $\mathrm{ml} / \mathrm{min}$ \\
\hline
\end{tabular}

\section{RESULTS}

In the following subsections, the results are presented subdivided according to the respective machining process. For each process and oil tested, tool life, cutting edge wear, force and surface finish are analyzed and compared with the reference mineral hydrocracking oil and the MWF emulsion cooling. All shown values are the mean values of the respective three experimental repetitions for each tested oil and as error bars the standard deviation.

\subsection{Milling}

The milling test is performed up to a maximum tool life of $\mathrm{Lc}=100 \mathrm{~m}$. The failure of the tool also leads to a premature end of the test. Either the maximum wear mark width VBmax, averaged over all four cutting edges of the respective tool, is above the defined wear mark width of VBmax $=200 \mu \mathrm{m}$ or there is a tool failure due to tool breakage or welded flutes.

The representation of the average tool life in Fig. 3 shows that longer tool life can be achieved with CMQL than with standard emulsion flood cooling, shown on the far right. The best results are achieved with NE 03 and KW 01 . Here, a tool life of $L C=100 \mathrm{~m}$ is achieved in every test run. On average, the natural esters and the natural hydrocarbons achieve the best results in terms of tool life when milling the stainless steel. In the group of synthetic esters, the oils SE 05, SE 06 and SE 09 showed the longest tool life. However, when using the synthetic oils, the required tool life of $L C=100 \mathrm{~m}$ could never be achieved in all three test repetitions. The process stability is consequently low.

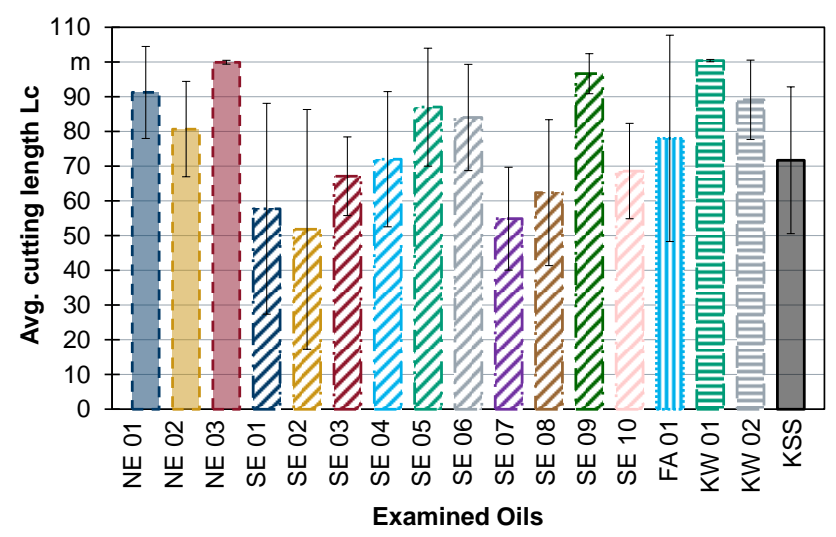

Fig. 3: Avg. cutting length Lc- milling.

The tool life of the milling tool is significantly influenced by the wear of the cutting edge. Fig. 4 shows the maximum wear mark width on the free surface of the cutting edges, plotted against the cutting length. With increasing cutting length, the wear mark width usually increases continuously in a linear fashion. The predominant wear pattern that leads to the unusability of synthetic esters is adhesive wear and the welding of flutes. When material adhesions are not present, edge rounding and small chipping are present on the cutting edges. With some bio-based oils, lower wear can be achieved than with the reference KSS. The natural esters were particularly convincing in this respect. However, KW 01 and the mineral reference oil KW 02 also resulted in low wear.
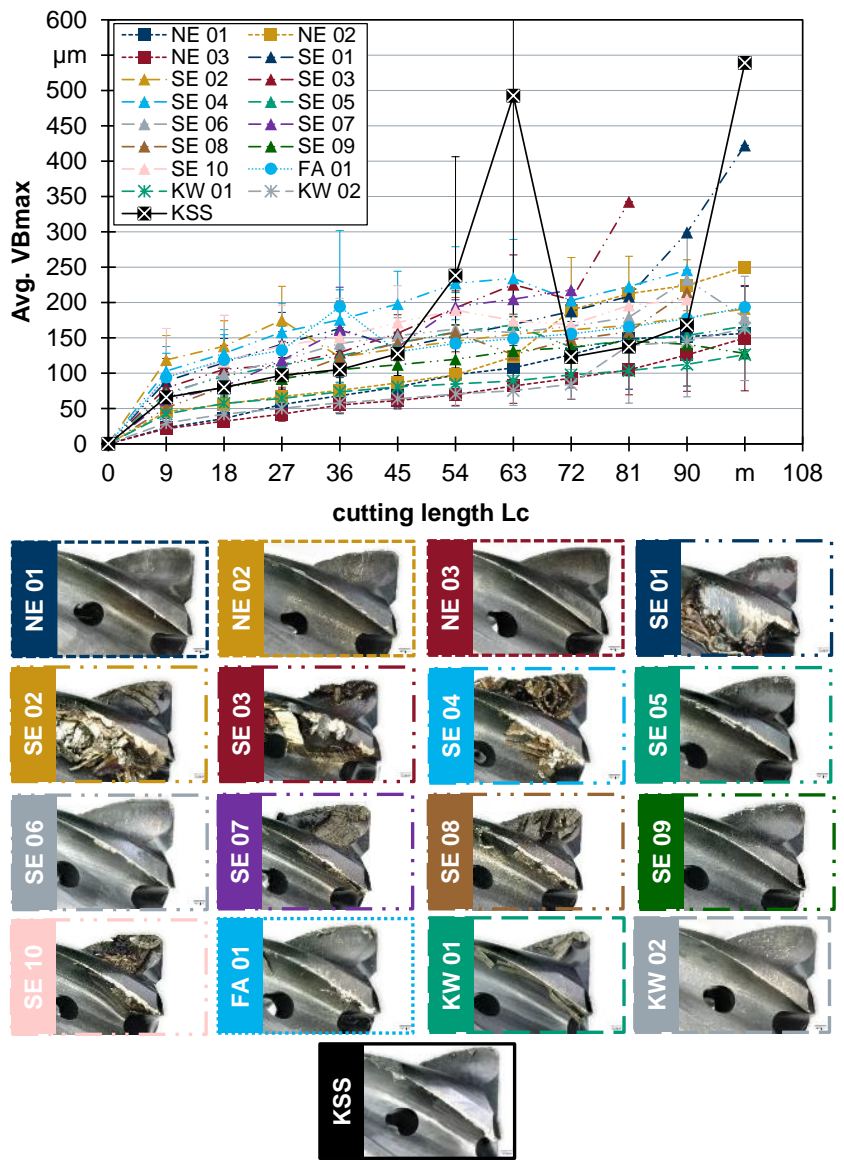

Fig. 4: Avg. wear Vbmax - milling.

With increasing cutting length and wear, the measured bending moment of the milling tool also increases. Abrupt tool failure due to tool breakage must be expected when bending moment is $>50 \mathrm{Nm}$. Strongly increasing bending moments are the result of reaching the max. wear mark width and clogged flutes.

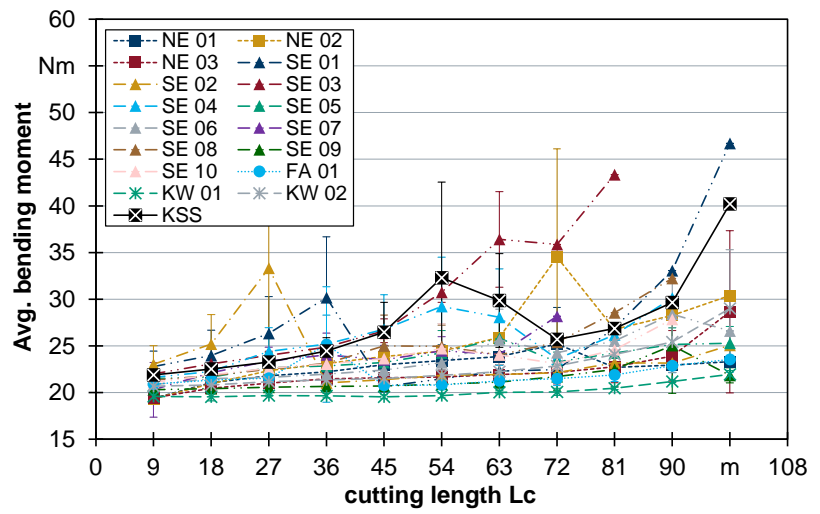

Fig. 5: Avg. bending moment-milling.

The recorded values are shown in Fig. 5. By using cryogenic minimum quantity lubrication with bio-based base oils, the bending moment over the entire cutting path 
length can be reduced in almost all cases compared to emulsion flood cooling. Most bio-based base oils lead to a bending moment of 20-25 Nm until shortly before the end of the tool life. The lowest bending moments were achieved by KW 01 and FA 01.

\subsection{Rough turning}

The rough turning tests are carried out up to a maximum cutting distance $\mathrm{Lc}=4000 \mathrm{~m}$. This corresponds to the turning of two test workpieces. Furthermore, the tests are terminated when the maximum flank wear is greater than VBmax $=400 \mu \mathrm{m}$.

In all test series and test repetitions, the required cutting length $L c=4000 \mathrm{~m}$ can be achieved. Based on the results, the maximum cutting path in future test series will be increased to three semi-finished products or Lc $=6000 \mathrm{~m}$.

Fig. 6 shows the average wear mark widths and wear patterns during rough turning. The wear increases predominantly linearly with increasing cutting length. The predominant wear is flank wear, crater wear is hardly present. Adhesions and material welds on the cutting edge are also visible in the rough turning tests. Furthermore, outbreaks of the cutting edge at the level of the cutting depth can also be seen in all tests. Only the oils KW 01, SE 03, SE 05 and SE 10 exceed the wear mark width limit of $V B m a x=400 \mu \mathrm{m}$ on average after $\mathrm{Lc}=4000 \mathrm{~m}$ and thus just about reach the required tool life $L c=4000 \mathrm{~m}$. In the case of the synthetic esters, only the wear mark width limit of $\mathrm{VBmax}=400 \mu \mathrm{m}$ is exceeded. Among the synthetic esters, only SE 09 remains below the limit. The best results are shown by the natural ester and fatty alcohol groups. Compared to CMQL, emulsion flood cooling leads to a significantly smaller wear mark width, which hardly increases over the cutting distance.
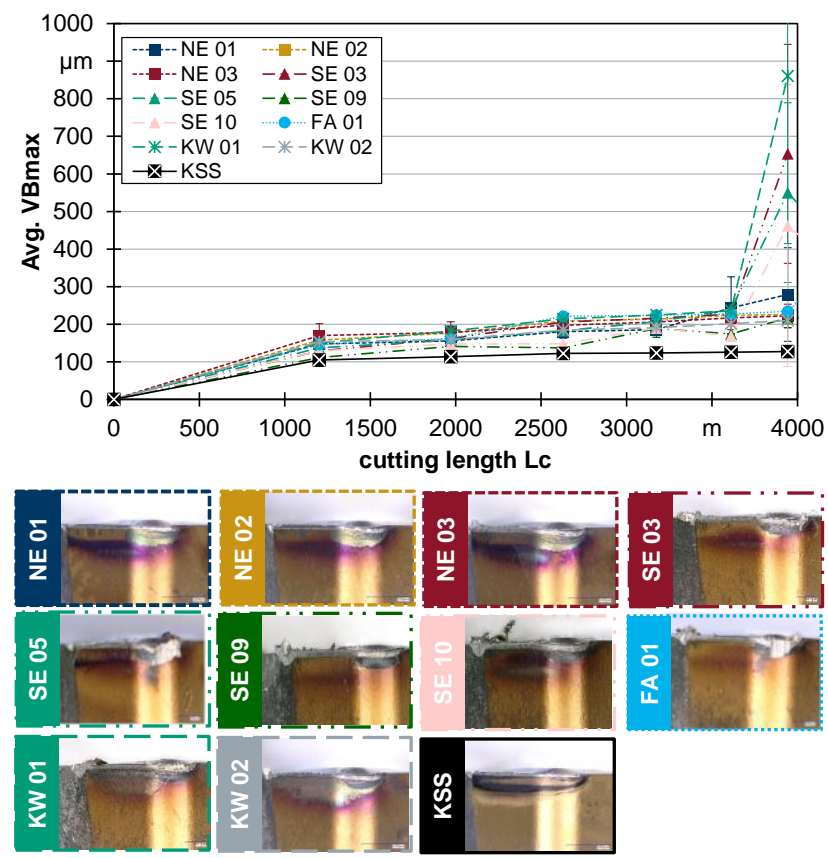

Fig. 6: Avg. wear Vbmax - rough turning.

By using CMQL, the average cutting force Fc can be reduced by $100-200 \mathrm{~N}$, compared to emulsion flood cooling, Fig. 7. When using the bio-based base oils with CMQL, SE 10 and SE 09 show the lowest cutting forces. However, it can be said that, in summary, all bio-based base oils are in a range of about $50 \mathrm{~N}$ difference only and thus very similar forces are present in all groups.

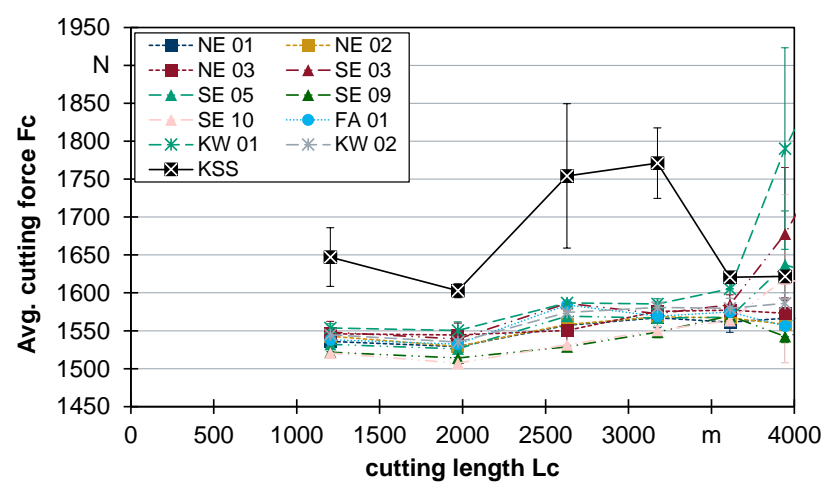

Fig. 7: Avg. cutting force Fc-rough turning.

\subsection{Finish turning}

For finish turning, the maximum tool life is set at $\mathrm{Lc}=10000 \mathrm{~m}$. This is achieved neither with emulsion flood cooling nor with CMQL, shown in Fig. 8. Therefore, in all tests, reaching the defined maximum wear mark width on the free surface of $\mathrm{VBmax}=200 \mu \mathrm{m}$ leads to reaching the end of the tool life and the end of the respective experiment.

The synthetic esters SE 03, SE 09, SE 10 and the fatty alcohol FA 01 achieve a smaller tool life than with emulsion flood cooling. Only the synthetic ester SE 05 shows better results. Especially with the natural esters and the hydrocarbons, longer cutting distances are achieved with CMQL than with emulsion cooling. Particularly noteworthy is the high test repeatability and consequently the process reliability when using NE 02, SE 05, KW 01 and the reference mineral oil $\mathrm{KW} 02$ for $\mathrm{CMQL}$.

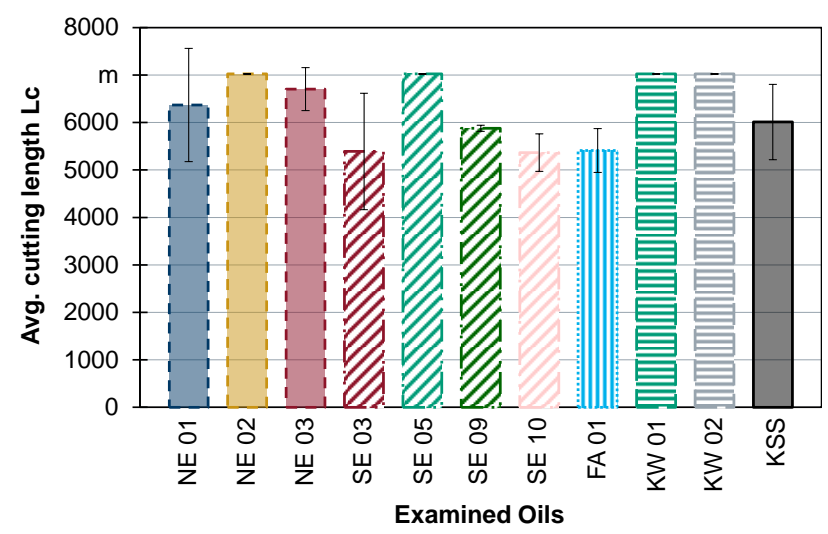

Fig. 8 : Avg. cutting length Lc- finish turning.

Fig. 9 shows the averaged wear mark widths and wear patterns of the free surface during finish turning. In contrast to milling and rough turning, there is no adhesive wear in finish turning. It is flank wear and cutting edge rounding. Crater wear is also present. However, this is smaller than the flank wear, which is why only the flank wear is explained in more detail here. After about half the cutting length, the use of CMQL results in a smaller wear mark width than with emulsion flood cooling. In general, it can be said that the wear also increases more continuously and linearly. Whereas with emulsion cooling there is a steeper increase at this cutting length. The value of the slope of the wear mark width characteristic curve is comparable for the biobased base oils. The largest wear mark widths were determined when using FA 01 and SE 03. 


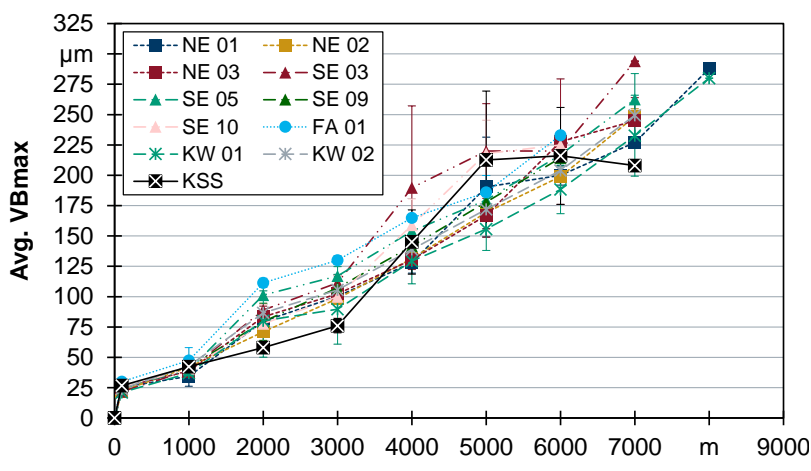
cutting length Lc
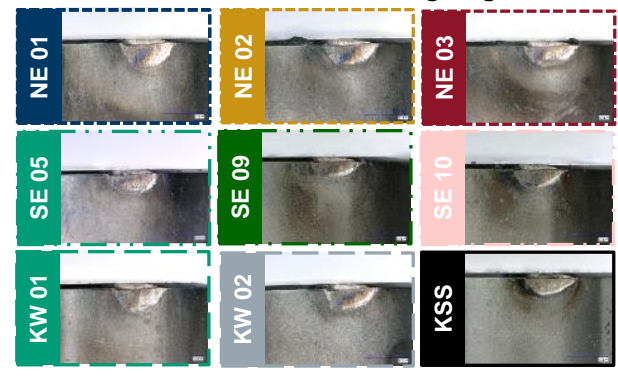

Fig. 9: Avg. wear Vbmax - finish turning.

The forces in finish turning are logically much lower than in rough turning due to the process parameters.

In finish turning, the use of CMQL reduced the cutting force compared to emulsion cooling, as shown in Fig. 10. Particularly noteworthy at this point are the base oils SE 03, FA 01 and KW 01. The use of these oils leads to a reduction of the cutting force $\mathrm{Fc}$ by more than half compared to the other oils but also to emulsion cooling.

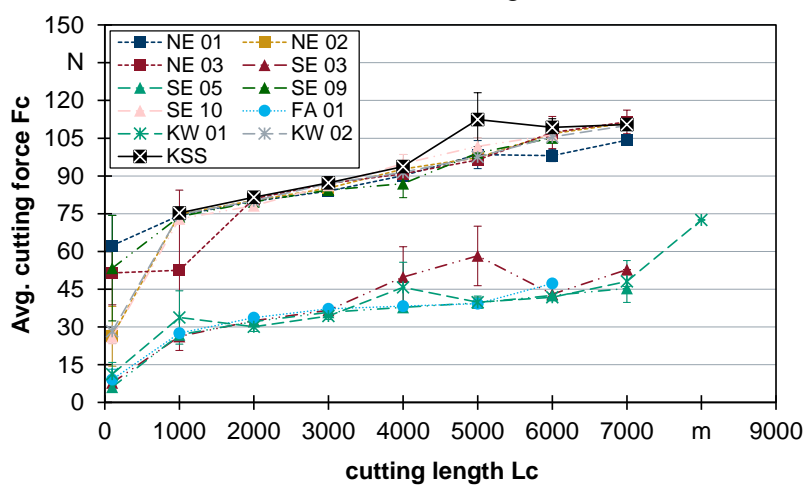

Fig. 10: Avg. cutting force Fc- finish turning.

\section{SUMMARY}

In summary, the bio-based base oils are suitable for use with cryogenic minimum quantity lubrication for milling, rough turning and finish turning of stainless steel X2CrNiMo17-12-2 (1.4404) and the rolling bearing steel $100 \mathrm{Cr} 6$ (1.3505). Even the unadditivated oils showed good results.

There is high potential in the use of natural ester base oils (In this study one natural ester base oil is based on coconut oil, one on rapseed oil, and one on sunflower oil, respectively) for cryogenic minimum quantity lubrication compared to conventional flood cooling with regard to:

- tool life

- $\quad$ wear mark width and pattern

- $\quad$ process forces (including tool vibration)

Resinification due to the use of bio-based oils and thus negative effects on the performance of the machine tool could not be detected in the extensive test series, neither in milling nor in turning. However, the test machining time is of course still not comparable with series production. In further investigations, it must be clarified whether the resinification effect in minimum quantity lubrication and the mostly residue-free evaporation has any relevant influence on the machine tool. On the other hand, a fine oil mist is generated which could be deposited on the machine components.

In order to increase the performance of the investigated biobased base oils, they are to be additivated in a second step according to the process requirements. Based on the results, the process of bio-based cryogenic minimum quantity lubrication will be transferred to industry in order to be able to directly compare the performance and to realize a knowledge transfer to industry.

\section{ACKNOWLEDGMENTS}

The results are part of the research project "ECO2il Development of bio-based metalworking oils for croygenic minimum quantity lubrication". Thanks go to the German Agency for Renewable Resources and the German Federal Ministry of Food and Agriculture for funding the joint project. The consortium of the individual sub-projects consists of one research institution (REP-Chair of FAU ErlangenNuremberg), three end user companies (Guehring KG, EagleBurgmann Germany GmbH \& Co. KG, Schaeffler AG) and three lubricant manufacturers (Fuchs Schmierstoffe $\mathrm{GmbH}$, Rhenus Lub GmbH \& Co KG, Blaser Swisslube $\mathrm{GmbH})$.

\section{REFERENCES}

[Abdalla 2007] Abdalla, H. S., et al. Development of novel sustainable neat-oil metal working fluids for stainless steel and titanium alloy machining. Part 1. Formulation development. The International Journal of Advanced Manufacturing Technology, 2007, Vol. 34, pp. 21-33.

[Abele 2012] Abele, E. and Sieber, M. Kohlendioxid schlägt MMS. WB Werkstatt + Betrieb, 2012, No. 11.

[Abele 2012]: Abele, E. Trockene Zeiten stehen an. WB Werkstatt + Betrieb, 2012, No.07, pp. 20-28.

[Bartz 2010] Bartz, W. J. ; Moeller and U. J. Expert PraxisLexikon Tribologie plus. Begriffe für Studium und Beruf. Renningen-Malmsheim, 2000.

[Baumann 1996] Baumann, W. and Herberg-Liedtke, B. Chemikalien in der Metallbearbeitung. Daten und Fakten zum Umweltschutz. Berlin and Heidelberg, 1996. ISBN 978-3-642-61004-2

[Belluco 2001] Belluco, W. and Chiffre, L. de. Testing of vegetable-based cutting fluids by hole making operations. Tribology \& Lubrication Technology, 2001, Vol. 57, No. 1, pp. 12-16.

[Belluco 2004] Belluco, W. and Chiffre, L. de. Performance evaluation of vegetable-based oils in drilling austenitic stainless steel. Journal of Materials Processing Technology, 2004, Vol. 148, No. 2, pp. 171-176.

[BGI/GUV-I 718 2010] BGI/GUV-I 718: Minimalmengenschmierung in der spanenden Fertigung, 2010.

[Biermann 2018] Biermann, D., et al. Mit Kälte smart ins Harte. WB Werkstatt+Betrieb, 2018, No. 4, pp. 18-21.

[Chiffre 2002] Chiffre, L. de and Belluco, W. Investigations of cutting fluid performance using different machining operations. Tribology \& Lubrication Technology, 2002, Vol. 58, No. 2, pp. 22-29. 
[Chiffre 2007] Chiffre, L. de, et al. Performance Testing of Cryogenic CO 2 as Cutting Fluid in Parting/Grooving and Threading Austenitic Stainless Steel. CIRP Annals, 2007, Vol. 56, No. 1, pp. 101-104.

[Czichos 2015] Czichos, H. Tribologie-Handbuch. Tribometrie, Tribomaterialien, Tribotechnik. Wiesbaden, 2015.

[Denkena 2018] Denkena, B., et al. Titanbearbeitung - das Hartmetall macht den Unterschied. VDI-Z Integrierte Produktion, 2018.

[Dettmer 2006] Dettmer, T. Nichtwassermischbare Kuehlschmierstoffe auf Baueis nachwachsender Rohstoffe. Braunschweig: Institut für Werkzeugmaschinen und Fertigungstechnik der TU. Essen, 2006.

[DGUV Information 209-051 2016] DGUV Information 209051. Keimbelastung wassergemischter Kühlschmierstoffe, 2016.

[DIN CEN/TR 16227 2011] DIN CEN/TR 16227, DIN SPEC 51523:2011-10. Fluessige Mineraloel-Erzeugnisse - BioSchmierstoffe - Empfehlungen fuer die Terminologie und Charakterisierung von Bio-Schmierstoffen und biobasierten Schmierstoffen, 2011

[Gross 2016] Gross, D. KryoLEAN: Nutzung CO2-basierter, kryogener Technologie zur Zerspanung und Reinigung. In: 3. Green Factory Bavaria Kolloquium 2016 Energieeffiziente Produktion.Nürnberg, 2016, pp. 77-87.

[Hanenkamp 2018] Hanenkamp, N., et al. Hybrid Supply System for Conventional and CO2/MQL-based Cryogenic Cooling. Procedia CIRP, 2018, Vol. 77, pp. 219-222.

[Herrmann 2017] Hermann, C., et al. Ökologische und oekonomische Bewertung des Ressourcenaufwands Wassermischbare Kuehlschmierstoffe, 2017.

[Hesterberg 2005] Hesterberg, S. and Wittkop, S. Prozesskonditionierung mittels Kohlendioxid bei der Drehbearbeitung nicht rostender Staehle. Essen, 2005.

[Hong 2000] Hong, S. and Broomer, M. Economical and ecological cryogenic machining of AISI 304 austenitic stainless steel. Clean Products and Processes, 2000, No. 3, pp. 157-166.

[Klocke 2008] Klocke, F. and Koenig, W. Drehen, Fräsen, Bohren. Berlin, 2008. ISBN 978-3-540-35834-3

[Lawal 2012] Lawal, S. A., et al. Application of vegetable oilbased metalworking fluids in machining ferrous metals-A review. International Journal of Machine Tools and Manufacture, 2012. Vol. 52, No. 1, pp. 1-12.

[Mannekote 2018] Mannekote, J., et al. Environmentally friendly functional fluids from renewable and sustainable sources-A review. Renewable and Sustainable Energy Reviews, 2018, Vol. 81, pp. 1787-1801.

[Park 2017]: Park, K.-H., et al. Milling of titanium alloy with cryogenic cooling and minimum quantity lubrication (MQL). International Journal of Precision Engineering and Manufacturing, 2017, Vol. 18, No.1, pp. 5-14.

[Pereira 2016] Pereira, O., et al. Cryogenic and minimum quantity lubrication for an eco-efficiency turning of AISI. Journal of Cleaner Production, 2016. Vol. 139, pp. 440-449. [Rahim 2009] Rahim, E. and Sasahara, H. Performance of Palm Oil as MQL Fluid during High Speed Drilling of Ti-6Al4V. The 5th International Conference on Leading Edge Manufacturing in 21st Century. Osaka, 2009.

[Reich 2002] Reich, S. and Boeswetter, G. Trockenbearbeitung-Moeglichkeiten und Grenzen einer Technologie. Thüringer Mitteilungen des VDI und VDE (2), 2002.

[Schebek 2016] Schebek, L., et al. Praxisleitfaden. Ressourceneffizienz in der Produktion-Zerspanungsprozesse. Hessisches Ministerium fuer Wirtschaft, Energie, Verkehr- und Landesentwicklung, 2016.
[VDI 3397 2007]: VDI 3397. Kuehlschmierstoffe für spanende und umformende Fertigungsverfahren, 2007.

[Walter AG 2018] Walter AG. Effiziente Zerspanung neuer Automobil-Werkstoffe. URL https://mav.industrie.de/ fertigung/werkzeuge/effiziente-zerspanung-neuer werkstoffe. review date 2018-03-08

[Wang 2000] Wang, Z. Y. and Rajurkar, K. P. Cryogenic machining of hard-to-cut materials. Wear, 2000, Vol. 239, No. 2, pp. $168-175$.

[Weinert 1999] Weinert, K. Trockenbearbeitung und Minimalmengenkühlschmierung. Einsatz in der spanenden Fertigungstechnik. Berlin, 1999. ISBN 978-3-642-58624-8 [Winter 2012] Winter, M., et al. Investigation of $A$ New Ecologically Benign Metalworking Fluid in Abrasive Machining Processes to Substitute Mineral Oil Based Fluids. Procedia CIRP, 2012, Vol. 1, pp. 393-398.

[Xavior 2009] Xavior, M, et al. Determining the influence of cutting fluids on tool wear and surface roughness during turning of AISI 304 austenitic stainless steel. Journal of Materials Processing Technology, 2009, Vol. 209, No. 2, pp. 900-909. 